\title{
THE FOREST IN THE NEOLITHIC OF NORTHERN EUROPE
}

\section{INTRODUCTION}

To date, the most sustained research into the woodland of the Neolithic has come from palynological studies, and the techniques of palynology provide a powerful tool for producing a site-based and regional picture of woodland development through time. In this chapter, the literature from south Scandinavia and the British Isles is reviewed to provide a picture of the woodland that Neolithic communities would have encountered in everyday life. Palynological and environmental studies more generally are not without their uncertainties and problems, but the data provided by these techniques provide an essential baseline for situating the day-to-day lives of communities who inhabited the Neolithic landscapes of northern Europe. As we will see, what the palaeoecological literature emphasises are the ways in which the landscapes of northern Europe were never stable, but always in a process of becoming.

\section{AFTER THE ICE}

After the end of the last Ice Age, woodland began to spread across northern Europe. By 11,000 cal BC, woodlands of birch, poplar, and pine had begun to colonise Britain and southern Scandinavia from woodlands further south. As the Holocene developed and warmer conditions continued to establish, the woodlands of northern Europe also expanded and diversified, and by the late Mesolithic, rich woodland environments had taken hold across most of northern Europe. Johannes Iversen, who first traced the impacts of people on the environment through his early palynological work in Denmark, pictured the Mesolithic forest as continuous, dense woodland interrupted only by areas of 
water such as rivers and lakes (e.g. Iversen 1941, 1967, 1969). Iversen presumed that large parts of the landscape would have been sparsely populated due to the density of the forest.

The picture of the environment of the Mesolithic as understood today is now somewhat different from that proposed by Iversen. The image of a closed Mesolithic forest, uninviting to settlement, has been revised, and it has been suggested by many scholars that impacts on the forest may not have been restricted to the Neolithic period, but occurred much earlier and throughout the Mesolithic. Mesolithic impacts on the forest have been suggested since the 1970s (e.g. Dimbleby 1985; Mellars 1976; Simmons 1996; Smith 1970) and the overall nature of the forest composition prior to agriculture has also been debated. In the early 1980s, for example, Rowley-Conwy attacked the Iversen model of a dark, dense Mesolithic wildwood, arguing that there would have been great variability in the forest with well-developed shrub and field layers and more open areas than Iversen suggested (Rowley-Conwy 1982: 204). Mellars (1976) and subsequent authors supported the idea of Mesolithic impacts on the 'wildwood', suggesting that small clearances may have been created to attract game and to promote the growth of nut- and fruit-bearing plants such as hazel, cherry, and crab apple (see also Göransson 1994a, 1994b: 169-71). Other studies have suggested more dramatic changes. In upland areas in northern England, for example, studies have suggested that extensive areas of open upland heath were encouraged by Mesolithic manipulation of the forest, and that in some areas heath creation in the Mesolithic may have been relatively large in scale (Caseldine and Hatton 1993; Edwards 1995; Edwards et al. 1995; Simmons 1996, 2001).

It is easy, however, to read too much into this evidence overall; the picture produced by many pollen records is of a relatively encompassing, mature, mixed woodland characterising the environment of the later Mesolithic (Huntley and Birks 1983). There may well have been some more open areas, as a result of a range of natural (and anthropogenic) causes (Brown 1997), but undoubtedly woodland played an important role in the majority of Mesolithic landscapes (Whitehouse and Smith 2010: 550). Recent studies in the Thames Valley, for example, suggest dense, mixed deciduous woodlands in the Mesolithic of eastern England (Barclay and Hey 2007). Similarly in Scania, south Sweden, an extensive pollen and plant macrofossil study suggests only very limited manipulation of woodland in the Mesolithic - overall the picture is of a largely forested environment in the areas of southern Sweden studied (Sjögren 2006: 79). In northern Britain, Mesolithic impacts have also had a long history of debate (see Tipping 1994, 2003, 2004 for summary and critique), but the evidence suggests that if Mesolithic impacts did occur they were small-scale, localised, and rarely permanent (with a few possible exceptions, e.g. Robinson and Dickson 1988). The continental background in 
Central Europe is also suggestive of relatively dense woodland in the Mesolithic with only limited clearings in the Neolithic associated with LBK settlement - with the naturally more open forest of river floodplains playing an important role in the early adoption of agriculture (Bakels 1978, 1992; Kreuz 2008; Modderman 1992; Pott 1992).

In 2000, Frans Vera published Grazing Ecology and Forest History, which critiqued the traditional view of Holocene forest history and questioned the picture of a dense wildwood in the European Mesolithic, arguing that palynologists had underestimated the amount of open ground in the period, failing to take into account the open areas that he argued would have been created by herds of large herbivores such as bison and red deer (Vera 2000; see also Marquer et al. 2014). Instead of dense forest, Vera suggested the Mesolithic forest was characterised by extensive open areas of grassland interspersed with solitary trees and small groves. Vera's ideas caused great controversy and soul-searching in palaeoenvironmental circles, and have since been undermined by a number of studies. Fraser Mitchell, for example, in a 2005 article using evidence from Ireland where large herbivores were not present in the Mesolithic, showed that Vera's suppositions were unfounded and that open canopy forest could be created only by human activity and that the evidence from across Europe was indicative of closed-canopy conditions (Mitchell 2005; see also Bradshaw et al. 2003 and Marquer et al. 2014 who continue the debate). This is not to say the forest would be homogenous and unchanging: there would have been open areas created by natural processes and perhaps human augmentation through burning, and the forest would have varied according to geographical and geological conditions (Brown 1997). Nonetheless, overall the forest would have been much denser and more developed than woodlands today, with no direct contemporary parallel (see Peterken 1996; Svenning 2002).

\section{THE COMING OF THE FARMERS}

As outlined in the introduction, the 41st-40th century cal BC appears to mark the introduction of farming to northern Europe. As well as being the period in which agricultural lifeways first reached northern Europe, the late 5th millennium $\mathrm{BC}$ to early 4 th millennium cal $\mathrm{BC}$ is also coincident with modifications in the arboreal vegetation, with a major decline in elm trees in northern Europe being one of most widely recognised changes. This phenomenon was once assumed to be caused by human impact on vegetation in the early stages of transforming the forest into an agrarian landscape (Parker et al. 2002). However, this link between the elm decline and the onset of farming is now seen as much more problematic, and a range of influences are now taken into account, with disease now regarded as the most likely culprit. However, 
the spread of disease may have been exacerbated by both climate change and humanly induced clearance of the forest (Friman 1997; Parker et al. 2002: 26). Recent dating evidence in Ireland has also questioned the synchronicity of the elm decline and suggests variation in the causes of its spread (Whitehouse et al. 2013: 16). Whatever the case, the beginnings of the 4th millennium BC are certainly accompanied by increased evidence for impacts on the forest, activities that include occasional indicators of agricultural practices such as cereal-type pollen, weeds associated with open areas, and grazing indicators.

In his important early studies on pollen history, Iversen proposed very particular interpretations of the evidence found in the early stages of the Neolithic in his landnam (land take) model. He believed there was great synchronicity to the impacts across Denmark and that they appeared to follow a particular pattern of increased evidence for fire, opening of the forest canopy, and agricultural indicators occurring for the first time. Iversen suggested this reflected the widespread clearance of forest by axe and fire for pasture and cereal growing in association with the first agricultural settlers in Denmark. He suggested that this occurred in a short burst of activity with new areas of forest being repeatedly opened as Neolithic groups moved to new areas and forest regenerated in the previously cleared areas (Iversen 1941, 1967, 1969). Iversen provides a concise description of his landnam model in a 1969 paper:

A considerable number of [Neolithic] people settled in an area and founded a settlement on a suitable spot. But first of all they had to clear the forest in order to provide feed for the cattle and open soil for the grain field. The primitive [primary] forest was quite unsuitable for grazing, being poor in grass and low bushes, but immensely rich in dead wood. Colonisation was therefore initiated with a forest clearance by axe and fire, and thereafter rapidly shooting trees, bushes and herbs would be ideal food for the cattle which moved about loose. When the regenerated forest had again become so dense that a new clearance would be necessary, there seems to have been a general preference for moving to a new spot; no doubt the primitive forest with all its dead, inflammable wood was easier to set on fire than the secondary fresh vegetation. (Iversen 1969 [2002]: 111)

Iversen drew parallels with traditional Finnish forest clearance by fire (Iversen 1941: 44) and the earliest colonising occupation of Iceland and Greenland, which were marked by extensive clearance (Iversen 1969: 109). Indeed, the evidence outlined by Iversen was often taken to mark the inevitable decline of the forest in Neolithic societies and perhaps promoted a rather minimal role for the forest in interpretive accounts, a situation that persists today. However, Iversen himself thought that clearances in the Neolithic were small in scale and that there would have been extensive forest grazing around clearances 
(Iversen 1967: 53), but this observation has been rather lost in more recent decades (see Edwards 1993).

Our understanding of the extent of forest impacts in the Neolithic is still debatable in many contexts. Different pollen sources will produce different qualities of information that are not necessarily easy or possible to reconcile. Pollen from bogs tends to give a very generalised picture of forest composition; more discrete sources, such as from small hollows, can be more reliable indicators of forest cover in a localised area. Mitchell's (2005) critique of the Vera model, for example, used a number of small hollow sources from southern Sweden, Denmark, and Ireland to show that tree pollen percentages remained high prior to 3,000 years ago. Mitchell suggested tree pollen percentages of over $60 \%$, as found in all of these small hollows, was indicative of a closedcanopy forest, a view shared by Svenning (Mitchell 2005: 172; Svenning 2002). These contexts, of course, only indicate the conditions in the vicinity of these hollows, and these are not always in close association with Neolithic sites or monuments; therefore, they only give a partial snapshot of the environment from localised contexts in the Neolithic. The more generalised pollen evidence also suggests that woodland continued to be the major landscape influence throughout the Neolithic. A comprehensive review is not possible in a study such as this, but a sample of recent and older research from across northern Europe points to variability and complexity of the Neolithic forest composition. The evidence outlined here is biased towards the British Isles, as that is where the author's knowledge is best, but recent work from southern Scandinavia suggests a comparable picture to that of Britain and Ireland.

\section{South Scandinavia}

In Sweden, the evidence for forest cover during the Neolithic is variable but generally indicates the continuing relevance of woodland to Neolithic lives. The evidence from pollen cores in Sweden, as elsewhere, is hard to tie to specific archaeological sites, but gives an overall impression of the levels of tree cover. In a series of palaeoenvironmental studies in association with the West Coast Rail Line Project in Scania, a number of pollen cores and other sources were analysed. The cores were examined according to broad chronological divisions. Analysis of the cores showed only weak indications of human impact in the period 4,000-3,400 BC, broadly corresponding with the earlier Neolithic (Sjögren 2006). In the period 3,400-2,800 BC, equating with the earlier part of the Middle Neolithic (the Middle Neolithic A), there were clear increases in evidence for human impact, but these consisted of limited forest clearings, probably primarily for grazing as little in the way of cultivation indicators was indicated (Sjögren 2006: 115). Like palaeoenvironmental evidence elsewhere in Europe, many of the larger clearings occurred in the later 
Neolithic/Early Bronze Age in the 3rd millennium BC, but even at this stage, large areas of forest still remained (Sjögren 2006: 116). Plant macrofossil evidence suggests fixed cultivated plots occurred from the early Neolithic onwards, but these are likely to have been small in scale - a form of garden agriculture with plots set amongst grazed and relatively unaltered woodland (Sjögren 2006: 136, 140).

In Scania the results of the West Coast Line Project can be compared with those of the Ystad Project (Berglund 1988). Here, various pollen cores were studied in association with an analysis of the landscape from the Mesolithic onwards. Differences were found between the levels of human impact on the forest in the Neolithic between coastal and inland areas, with some inland areas remaining largely unaffected by clearance (Berglund 1988: 250). Again, the great expansions in woodland clearing only occurred from the mid-Bronze Age onwards (Berglund 1988: 252). The West Coast Rail Line Project and the Ystad Project represent only two major synthetic projects on the Swedish prehistoric environment. Nonetheless, both suggest the localised and patchy nature of human impact in the Neolithic (Sjögren 2006: 121).

In Denmark, the evidence for Neolithic impact on the environment is also regionally variable, but some general patterns can be traced. Aaby (1986), in a study of three detailed pollen cores from Denmark, detected varying impacts in the Neolithic phases of these cores. There appears to have been a gradual opening up of the landscape during this period, but tree pollen percentages remained high throughout this phase suggesting that woodland continued to be a significant part of the landscape (Aaby 1986: 75). Fluctuations and re-establishment of woodland, as evidenced in some cores, also suggests land clearance did not follow a linear progression in all areas towards increasingly treeless landscapes. Some cores also suggest very little impact indeed - a core from Fuglsø bog, for example, has very high tree pollen percentages throughout the prehistoric period. In other locations, major clearances did not occur till the Early Bronze Age. At Abkœr in Jutland, for example, herb species indicative of open ground increased throughout the Neolithic but just reached up to $5 \%$ of the total pollen deposited (Aaby 1988: 217). It was only in the Medieval period that this area was substantially open (Aaby 1988: 217). In these cores, while tree pollen percentages in the Neolithic were high, this does not necessarily indicate homogeneityin all diagrams, different compositions and characters of woodland are suggested from primary lime-dominated woodland to landscapes characterised by scrub birch-hazel woods and/or managed coppices (Göransson 1994a, 1994b). These were landscapes characterised by mosaics of vegetation, but in most, if not nearly all cases, woodland of some kind continued to be present in the environment, perhaps highly modified in close proximity to Neolithic settlements and monuments, but elsewhere retaining the character of the woodland that had dominated Mesolithic landscapes. 
Svend Andersen's work in Denmark in the 1990s, where soil pollen records were compared to regional pollen sources, indicates in more definitive ways the heterogeneous nature of the forest through the 4th millennium cal BC (Andersen 1992). The elm decline in Denmark occurred approximately 4,000-3,800 cal BC in eastern Jutland and a little later in Zealand. In both eastern and western Denmark, the elm decline was accompanied by only slight changes in the overall forest composition, and occurrences of open indicators and cerealtype pollen in pollen cores are rare. As the 4th millennium progressed, there were rises in hazel and birch at the expense of lime, which would have made up the dominant part of Mesolithic forests, but overall the non-tree pollen percentages remained low and rarely exceeded $10 \%$, indicative of only limited opening of the forest (Svenning 2002). This suggests that while the composition of the forest was being altered, overall the dominant vegetation type was woodland, albeit indicating some form of management or maintenance of the forest.

Soil pollen samples from below Neolithic sites (see Chapter 4) provide a picture of the environment in close proximity to Neolithic activity areas. At early Neolithic sites, there is evidence for undisturbed primary lime-dominated woodland but also evidence for small-scale clearance activities and the regeneration of secondary birch and hazel woodlands in abandoned areas (Andersen 1992: 166, 171). In the middle Neolithic A $(3,400-2,700 \mathrm{BC})$, there is increased evidence for open coppice woodlands and the burning of these in clearance events to provide areas for pasture and cultivation. There is a general trend for more open indicators and less tree pollen at these sites through time; however, nearly all sites show that trees and woodland made up at least an element of the surroundings of these activity areas throughout the 4th and into the 3rd millennium BC. The total tree pollen from soil profiles in association with these sites varied from 20 to $99 \%$, indicating variability in tree composition around these locations. Nonetheless, even the middle Neolithic sites still indicate lime woodland was at least a component of the surrounding environment of these sites, suggesting woodland retained some of its late Mesolithic character over the longer term. These soil pollen profiles provide detail to the overall picture provided by regional cores and are more readily associated with Neolithic activity zones. The findings indicate that even in heavily utilised areas (many of these sites were settlements before becoming monumental barrows - see Chapter 4), woodland was still a component of the immediate settings of many sites.

Other pollen sources suggest more comprehensive, but rarely permanent, changes in the woodland composition in Denmark. A core from a small hollow at Næsbyholm Storskov, Zealand, for example, analysed by Andersen, suggested dramatic alterations in the early Neolithic, but also phases of regeneration and abandonment. The core shows clearance of many of the trees in the vicinity of the hollow in a short phase in the early Neolithic. Nonetheless, the 
clearance was not total - lime trees appear to have been maintained, possibly for use as leaf fodder (Andersen 1988). This phase was succeeded by the regrowth of an open hazel, oak, alder, and ash woodland with indicators of pasture. This area was used for pasture for around 500 years and then abandoned, allowing regeneration of the woodland near to its original makeup (Andersen 1988). This sequence reminds us that landscape change in wooded environments can be dramatic, but not permanent - the forest can act to counter human attempts to control and limit its presence and can equally rapidly regenerate to previous conditions.

\section{Britain and Ireland}

The British Isles have a long tradition of palynological investigations dating back to the 1920s (Fyfe et al. 2013: 134). In Britain and Ireland there are particularly good pollen records, especially in areas with more upland landscapes such as Scotland and Ireland, due to the greater numbers of wetland areas that help preserve pollen (Edwards 2004; Tipping 1994). In Scotland, the palynological record suggests the dominant vegetation cover throughout the Neolithic was woodland (Tipping 1994, 2004). The composition of woodland depended upon soil type, latitude, and a range of other factors. The broad-scale distribution patterns of tree types have been mapped for Scotland by Tipping (1994) and augmented in subsequent studies (e.g. Edwards 2004: fig. 5.2). In lowland eastern and southern Scotland, the woodland at the beginnings of the Neolithic was oak dominated, with hazel, elm, pine, and birch making up the understorey. In northern Scotland, pine forests dominated and in the island archipelagos of the north and west, scrub-like birch and hazel woodlands occurred (Edwards and Whittington 1997). The Scottish Islands undoubtedly had less forest cover extending back into the Holocene. Orkney had little in the way of forest cover by the late Neolithic, and the Western Isles show a steady decline in forest cover with perhaps only $10 \%$ forest cover by the Early Bronze Age (Dickson 2000; Fyfe et al. 2013: 136; Tipping 1994). The woodland in these contexts was replaced by a mix of heathland and grassland, but some woodland did remain in these locales until the later prehistoric period (Dickson 2000; Tipping 1994). Islands in the southwest of Scotland, in contrast, show greater levels of forest cover. On parts of Islay, for example, forest cover remained high (65-75\%) till the later Neolithic to Early Bronze Age when woodland/shrub cover was halved and grassland increased (Fyfe et al. 2013: 138).

On the Scottish mainland, woodland cover reached a maximum in the mid5th millennium cal BC. On mainland Scotland in general, the scale of forest clearance appears to have been relatively limited till the Bronze Age or later. New techniques of modelling pollen have shown that the vegetation cover during the later Mesolithic and earlier Neolithic was rarely stable and was 
subject to continual change (Fyfe et al. 2013: 138). While woodland generally began to decline from the early 4th millennium cal BC (Fyfe et al. 2013: 144), many pollen diagrams from mainland Scotland show limited evidence for woodland clearance (Tipping 1994, 2004, 2007). There were undoubtedly some impacts on the forest: the scale of Neolithic monumentality in this period and the pollen evidence suggest clearances were made; however, they did not affect the general woodland dominance of lowland landscapes. This does not mean that agriculture was not taking place, nor that woodlands were not being cleared - the early Neolithic in particular often has evidence for increased open indicators and the first occurrences of cereal-type pollen - undoubtedly human manipulation of the forest increased with the adoption of agriculture (Tipping 1994: 32). Cereal-type pollen is particularly important as it can give direct evidence for the introduction of domesticated plants, though there are difficulties at times in differentiating cereal pollen from that of wild grasses. There are also often rises in charcoal that in some cases might be linked to burning areas of woodland during clearance episodes.

Thus, we can identify in many palynological studies from mainland Scotland clear evidence for changes in the forest in the early 4th millennium cal BC that in some cases at least can be directly attributed to the beginnings of farming. Nonetheless, we should be careful not to overemphasise this change. In the later Neolithic in Scotland from around 3,200 cal BC, many pollen diagrams show regeneration of woodland to levels akin to those found before the beginnings of the Neolithic, though this is not a universal trend (Fyfe et al. 2013: 138; Tipping 1994: 32). In places where woodland regenerated, activity may have simply shifted focus to new locations, but this is another reminder that woodland change in the Neolithic was by no means necessarily permanent or irreversible.

Across mainland Scotland, while basic trends can be detected, patterns of vegetation cover were also regionally, locally. and chronologically variable (Fyfe et al. 2013: 138). Different modelling techniques can reveal new detail on landscapes at local levels. A localised soil pollen source in association with a major Neolithic timber building at Crathes, Aberdeenshire, in northeast Scotland, for example, has provided some resolution to landscape change at a sitebased level (Tipping et al. 2009). Simulation modelling suggests that a large and unusual timber building existed in a clearing that could have been as much as $2 \mathrm{~km}$ in extent. This clearing appears to have been used for growing cereals, but even here there was an element of tree cover with patchy stands of hazel (perhaps coppiced) occurring in between the cereal plots. The building itself, constructed in the first half of the 38th century cal BC, was built using very substantial oak timbers, suggesting that dense old-growth woodland stands were not far away (Murray et al. 2009). Indeed, pollen cores from the surrounding environment suggest that woodland cover was the dominant 
constituent of the landscape in the wider region, albeit the type of clearances detected at Crathes would be difficult to detect in the overall regional patterns that most pollen sources reflect (Tipping et al. 2009: 148). Bayesian modelling of the dates for the Neolithic suggests that hall buildings like Crathes were built a few generations after the beginning of the Neolithic in southern and northeastern Scotland (Whittle et al. 2011: 822, 863). The pollen work at this site, like Andersen's work in Denmark, shows how localised sources obtained in association with or near to Neolithic sites have strong potential to add detail to the wider patterns of landscape use and appearance in the Neolithic.

In Ireland, decline in woodland cover and evidence for Neolithic farming is variable, ranging from major clearances over hundreds of years to much smaller-scale (temporal and spatial) impacts, to little or no detectable change whatsoever (Mighall et al. 2008; O'Connell and Molloy 2001). The most recent general study of vegetation in Ireland suggests that opening of the forest canopy occurred from the early 4th millennium BC onwards (Whitehouse et al. 2013: 19). This study involved a re-evaluation of the palaeoenvironmental data from Ireland and associated dating evidence. Pollen evidence from multiple sites was collated and chronological data correlated where possible, and the timings of major palynological 'events' such as the elm decline and a rise in ribwort plantain (an agricultural indicator) were modelled. The elm decline was detected in most diagrams, but the synchronicity of the event across Ireland was found to be questionable. Early agriculture was found to have left a strong signature in some pollen records (e.g. the Céide Fields area, Co. Mayo), but in many others agriculture only had a very weak signature in the regional pollen evidence (Whitehouse et al. 2013: 19). Analysis of the plant weeds suggests that domesticated plants in the Neolithic were cultivated in intensively maintained garden plots that would have had only limited impact on the wider environment. Here, landscape usage was evidently not uniform, creating a 'spatially heterogeneous landscape of varying intensity and use depending upon local circumstances and population densities' (Whitehouse et al. 2013: 19). In the earlier phases of the Neolithic in Ireland there was a significant horizon of change in the late 38th-late 37th centuries cal BC when significant numbers of timber longhouses were constructed, and there is clear evidence for mixed agriculture including the growing of crops such as emmer wheat and barley in small fixed plots (Smyth 2014: 41-50; Whitehouse et al. 2013; Whittle et al. 2011: 807-8). In the period after 3,500 cal BC, in the middle Neolithic in Ireland, impacts on the environment become harder to detect, and the archaeological and archaeobotanical record also suggests alterations in landscape use and economy at this time. Evidence for agricultural weeds such as ribwort plantain become much less visible in the second half of the 4th millennium BC from 3,400 cal $\mathrm{BC}$ onwards and there are signs of re-afforestation in some regions (Whitehouse et al. 2013). 
More detailed analysis at a site-based level in Ireland can add significant detail to the overall patterns available for the Neolithic environment. One site with strong evidence for earlier Neolithic forest clearance and utilisation in the Neolithic is located in the Glenulra basin near the northwest coast of Ireland. This is perhaps unsurprising, for in the basin lies one of the most extensive areas of Neolithic field systems yet identified in western Europe - the Céide Fields, constructed in the period 3,700-3,200 cal BC, probably in the earlier part of that chronological horizon (Whittle et al. 2011: 807). The environmental evidence for this location indicates that in the 5th millennium cal BC and beginnings of the 4 th, the landscape was heavily wooded, dominated by pine (O'Connell and Molloy 2001: 103). From 3,700 to 3,400 cal BC there was a sharp decline in tree cover, dropping from around $80 \%$ to just above $20 \%$ in the total pollen count during this period, the same period when the field system is most likely to have been constructed. Accompanying this was a rise in open-ground indicators such as ribwort plantain (Plantago lanceolata). An increase in landscape openness and a decrease in trees at this time can be expected considering the extensive nature of the field system here. The pollen evidence emphasises pastoral activity, and this tallies well with the nature of the field enclosures, but there are also some indications of small-scale cereal cultivation ( $\mathrm{O}^{\prime}$ Connell and Molloy 2001: 104). In the space of around 300 years, therefore, the environment appears to have changed dramatically, from a densely wooded landscape to an open, pastoral, enclosure-defined one. However, equally transformative is the apparent return to wooded conditions. Around 3,400 cal BC the tree pollen percentages rise sharply in an even more dramatic fashion than they declined, and by 3,100 cal BC there was a return to major woodland cover (O'Connell and Molloy 2001: 106). Open indicators decline at the same time, and after 3,100 cal BC oak, a tall canopy tree, increased to higher levels than ever before - the earlier 5th millennium and early 4th millennium cal BC character of the forest returned.

Other work in this region of Ireland provides further nuances to the overall trends and patterns in landscape character in the Irish Neolithic. A pollen diagram from an extensive bog around $16 \mathrm{~km}$ to the south of the Céide Fields at Garrynagran, for example, gives a more generalised picture of the region than the Glenulra core. Here, the area includes a number of court tombs that are likely to date to the earlier Neolithic period (O'Connell and Molloy 2001: 108). At Garrynagran, from the beginnings of the 4th millennium $\mathrm{BC}$, there was a very gradual decline in tree pollen percentages till around 3,500 cal BC. From around 3,500 to $3,350 \mathrm{cal} \mathrm{BC}$, there is a marked dip in total tree pollen percentages and open indicators increase; from 3,300 cal BC onwards, tree cover returned to very high levels. In the same period the overall tree pollen percentages dropped to around $80 \%$, much higher than the lowest levels at the Céide Fields. Nonetheless, the Garrynagran core is from a source that is likely to 
give a less localised signature than the Glenulra basin core; it therefore gives a general regional impression of widespread small-scale clearance events, but an overall environment where woodland continued to play an important role (O'Connell and Molloy 2001: 110). In both of these records, potential clearance events were restricted to the earlier Neolithic and were of different durations. The emphasis appears to have been on pastoral activity. Both indicate increases in tree cover from 3,400 to 3,300 cal $\mathrm{BC}$ with a return to fully wooded conditions by $3,100 \mathrm{cal} \mathrm{BC}$.

These two diagrams represent the stronger end of the spectrum of woodland disturbance noted in the overall patterns identified by O'Connell and Molloy in a review of the pollen evidence from Ireland (O'Connell and Molloy 2001). Their study involved the examination of the records from 34 locations. In those cores where some clearance could be identified there were approximately equal proportions of weak, medium, and strong evidence for forest clearance and pastoral use in the earlier Neolithic ( $\mathrm{O}^{\prime}$ Connell and Molloy 2001: fig. 10). Around $15-20 \%$ of cores showed little evidence for earlier Neolithic impacts or evidence for agricultural use. In the later Neolithic, two-thirds of pollen sites show little evidence of agricultural indicators and two-thirds show evidence of forest regeneration. There are problems in pollen dispersal that complicate this picture, such as the fact that canopy disturbance can increase tree pollen production, masking woodland decline, but equally, phenomena such as the elm decline and dying-off events through natural causes can also increase open indicators that can be mistaken for human impact ( $\mathrm{O}^{\prime}$ Connell and Molloy 2001: 118). Overall the Irish evidence is suggestive of localised and regional variation, with some landscapes witnessing little change while others underwent much greater alterations that resulted in significant openings in the forest. However, even where instances of significant opening of the forest can be identified, clearance was not necessarily permanent, and the process of changing woodland cover was not a linear process solely in favour of opening up the landscape: in the long term there was significant landscape flux. The extent to which some of the landnam events of the earlier Neolithic were entirely human-driven or whether other processes caused these openings or at least exacerbated human-driven change, is also uncertain.

The regeneration of forest in the later Neolithic is also complex in that it is uncertain whether this represents actual reductions in human activity, greater pollen dispersal through higher levels of woodland management, an altering economy, or even major hiatuses in farming through problems with crop yields as a result of disease (e.g. Dark and Gent 2001; Stevens and Fuller 2012; Whitehouse et al. 2013). Some of these questions are at present irresolvable, but the pollen evidence suggests that only a small proportion of landscapes witnessed large-scale clearing events in the Neolithic and that while these clearings were of longer duration than people such as Iversen originally 
envisioned in his landnam model, they were rarely permanent and did not necessarily coalesce with time. Some places such as the Céide Fields would have resembled the familiar open landscapes of Britain and Ireland today, but even here the landscape was never fixed or unchanging - within a few centuries the Céide Fields were retaken by forest and partly subsumed by bog growth.

The environmental evidence from England is more patchy than the evidence from Scotland or Ireland, with fewer suitable sites for traditional pollen analysis. Where sources are present, the evidence suggests variability depending on region and topography (Hodgson and Brennand 2006). However, it is perhaps worth dwelling on the English evidence as recent studies support the idea of significant regional variation. In northern England, for example, the palynological record ranges from little evidence for change in woodland composition in the Neolithic to evidence for heath expansion and agriculture in the uplands and some evidence for clearance in the lowlands (Beckensall et al. 2006: 23). In southern England, as in other regions, woodland varied according to geology. For example, lime, oak, ash, and elm woodland dominated on the chalklands and limestone areas of the Cotswolds, the Mendips, and Wessex, whereas the contrasting geology of areas such as Somerset, Devon, and Cornwall were dominated by oak-hazel woodland (Wilkinson and Straker 2008: 107). The elm decline in the southwest occurred around 3,700 cal BC, and this led to some opening of the woodland; nevertheless, most pollen profiles suggest that woodland grew back (Wilkinson and Straker 2008: 108). Thereafter, the majority of clearances appear to have been small scale and temporary. In the Thames Valley, for example, some areas witnessed clearance early in the Neolithic, but overall much woodland remained throughout the period. Shifting clearings may have been present within a gradually opening tree canopy (Barclay and Hey 2007: 403; Robinson 1992). The evidence for early Neolithic sites in the Thames Valley suggests woodland formed the background for activity at these locations and that there were few permanently open areas in the woodland of the 4th millennium BC (Barclay and Hey 2007: 404; Robinson 2000: 33).

There were, nonetheless, some areas that perhaps witnessed greater change, with particular areas of the chalklands in southern England having more open conditions at an earlier date than elsewhere (Allen and Gardiner 2009). For example, in the Upper Allen Valley, Dorset, an area that saw extensive Neolithic activity, woodland development in the Mesolithic appears to have been patchy with open areas present throughout the Holocence (French 2009; French et al. 2003; French et al. 2005). Parts of the valley also appear to have consisted of largely open grassland from the earliest Neolithic; however, the picture is not consistent. The earlier Neolithic palaeoenvironmental evidence suggests a mosaic of landscapes, with some early Neolithic monuments in this area, such as at Handley Down, located within only localised clearings in mature ancient 
woodland. On the other hand, the long barrows at Thickthorn Down and Gussage Cow Down, a tradition of monumentality that was constructed from the 39th century cal BC into the later 4th millennium cal BC (Whittle et al. 2011: 723), suggest established open grassland in the vicinity. By the later Neolithic, in the 3rd millennium cal BC, molluscan evidence from later Neolithic pit sites and henge sites such as Wyke Down and Knowlton are suggestive of open environments of maintained grassland with woodland only at the peripheries of each site (Allen 1998; French et al. 2003: 229). The open parkland landscape detected in the Allen Valley was most marked around Gussage Cow Down to Wyke and Bottlebush Downs - locations where major Neolithic monuments were built.

Recent work in the Stonehenge landscape adds significant detail to our knowledge of the chalklands of this key area of prehistoric Britain (French et al. 2012). Woodland development appears to have been slow and partial in the Mesolithic, with intermittent evidence for woodland modification. The landscape appears to have become more open in the later Mesolithic and earlier Neolithic. By the later Neolithic, this was a relatively open landscape; however, there were elements of primary and secondary woodland still present in the landscape at this time (see also Allen 1997; Allen and Gardiner 2009). The low ground was predominately grassland with some areas of arable land, but in the higher parts of the down woodland cover remained into the 2nd millennium cal BC. Molluscan evidence from Durrington Walls henge suggests the transition from partly wooded conditions to open grassland occurred some time prior to the construction of the henge in the 26th-25th centuries cal BC (Parker Pearson et al. 2007: 634). It was not until the early Iron Age (800-500 cal BC) that this landscape was completely cleared, with increased arable agriculture occurring from this period onwards. As at Cranborne Chase, the focus of the most extensive grasslands were concentrated around where the densest concentrations of late Neolithic monuments were constructed (Allen and Gardiner 2009: 61; French et al. 2012: 30).

Not all areas of the English chalklands were the same. East of the Allen Valley, in the Ouse Valley, pollen evidence suggests only small temporary clearings in the earlier Neolithic following the elm decline and re-establishment of woodland in the later Neolithic through processes of secondary succession (Waller and Hamilton 2000: 268-9). Around Rimsmoor, near Wareham in Dorset, the forest appears to have been opened around the time of the elm decline, and witnessed later localised clearings, but there was also some forest regeneration - permanent and large-scale clearance did not occur until the later Bronze Age (Waton 1982). Outwith the Wessex area generally, there are much sparser indicators of substantial clearance or open areas in the Neolithic environment (Wilkinson and Straker 2008: 115). The South Downs chalklands, for example, have much more routine evidence for developed forest soils and closed-canopy woodland (Allen and Gardiner 2009: 61). 
In upland areas of southern England, palaeoenvironmental evidence suggests that Neolithic impacts were limited (Wilkinson and Straker 2008: 111). For example, the Exmoor uplands appear to have experienced only minimal human impact in the Neolithic (Fyfe et al. 2003). At this location, woodland was reduced in association with the elm decline, but the former character of the woodland regenerated within a period of 50-200 years, indicating a shortlived temporary clearance (Fyfe et al. 2003: 227). The valley bottoms in this same region may have seen more concentrated woodland clearance, but the main opening of the landscape, as in many locations, did not occur till the Bronze Age. On Bodmin Moor, anthropogenic indicators are sporadic in the Neolithic levels of the pollen cores - human activity in the Neolithic is likely to have been seasonal or intermittent and generally small scale in nature. As is common elsewhere, the major expansion and opening of the landscape on the moor occurred in the Bronze Age, with a peak of activity in the 2nd millennium cal BC (Gearey et al. 2000: 503). We have only limited evidence for other upland areas: Caseldine and Hatton (1996) suggest that Dartmoor was largely an open landscape by the later Neolithic/Early Bronze Age due to climate change and expansion of peat along with the maintenance of open areas by grazing, but the exact nature of the Neolithic environment in this area is only partially understood (Wilkinson and Straker 2008: 111). In upland areas, the nature of forest clearance is complicated by changes in climate and specifically increased soil moisture levels that may have led to natural thinning of the woodland (Gearey et al. 2000: 502).

In the coastal lowlands of southern England, in places such as the Severn Estuary or East Anglia, landscape change in the Neolithic was accelerated by alterations in the sea level, which led to the inundation of former areas of land and consequent transformations in landscape character. Sea-level rises in the Severn Estuary, for example, led to the dominant alder carr woodlands being partly replaced by reed swamp and tidal mud flats (Wilkinson and Straker 2008: 112). Sea-level rise in East Anglia also led to dryland becoming waterlogged throughout the Holocene, pushing the woodland cover further inland and leading to vegetation change close to the coast (Sturt 2006: fig. 4.5). Human impact also led to modifications in the vegetation. At Haddenham in Cambridgeshire there are indications of substantial clearance in the early Neolithic, with particular impacts on the lime woodland, but some of these changes were also caused by rises in groundwater, which led to the replacement of alder carr around the Ouse channel by sedge fen and reed swamp (Peglar 2006: 28). In the later Neolithic, there was some regeneration of woodland and noticeable decreases in open species indicators and indicators of human activity, concurrent with regrowth in woodland and a diminution in cleared areas (Peglar 2006: 29). In East Anglia generally, Neolithic impact on 
woodland was probably small-scale in the early centuries of the 4th millennium cal BC, but clearance was well advanced on the fen edge and in lower parts of river valleys by the mid-4th millennium cal BC (French 2009: 89). In the Somerset Levels, the picture is mixed, with some evidence of clearance but also other phases of regeneration (Becket and Hibbert 1979: 37). Overall, extensive clearance did not take place until the earlier to mid-Bronze Age, and tree pollen percentages remained over $50 \%$ in the early Iron Age phases of the environmental record for this area (Beckett and Hibbert 1979: fig. 12; Wilkinson and Straker 2008: 113).

Further north, in the English East Midlands, there are reasonably detailed records, including very useful comparisons of differing palaeoenvironmental data sets. Overall, the regional pollen evidence for this area suggests only minor Neolithic impacts on the landscape in the 4th millennium cal BC (Clay 2001: 6; Hicks 1972). Pollen obtained from palaeochannels, a more localised source, adds important detail. Most profiles from these sources show largely undisturbed mixed woodland throughout the 4th millennium. Nonetheless, these sources can also produce a more nuanced picture, showing some areas of clearance that contrast with regional sources (Brown 2000; Clay 2001: 6). In the Raunds area, for example, an extensively studied area of monuments in Northamptonshire around the River Nene, important localised and regional differences in environment have been identified. Charred remains of grass tubers from the use of turf in an early Neolithic mound from West Cotton, for example, suggest that some areas of grassland occurred in the Nene Valley from the early stages of the Neolithic. Insect evidence from a nearby early Neolithic long barrow also suggests clearance of woodland prior to monumental building; however, the pollen evidence suggests that the monument was set against a background of woodland that differed little from the later Mesolithic contexts (Campbell and Robinson 2007: 23). Monuments continued to be constructed in the later Neolithic in the area, and these may have been set in localised clearings, but the pollen evidence from the valley shows that woodland continued to dominate the wider landscape.

Pollen analysis from sediments in a palaeochannel a short distance downstream from the monuments in the Nene Valley indicates alder growing around the riverbank and significant proportions of oak, hazel, and other tree types growing in the wider landscape in the later Neolithic (Campbell and Robinson 2007: 24-6). Insect evidence from the same palaeochannel also included major woodland indicators including rare and extinct species of woodland insects, suggesting mature areas of woodland with little parallel today. There were some open areas, but the evidence does not indicate intensive activity in terms of grazing or agriculture. Indeed, many of the locations in which monuments were built, while they were initially constructed in open areas, saw the 
regeneration of scrub woodland after a short period of time (Campbell and Robinson 2007: 26). Overall, the evidence from this area of the Nene river valley suggests temporary clearance for settlement and monument building in an environment dominated by woodland - clearances occurred, but these were generally small in scale and rarely long-term. Some monuments may have been constructed in a more permanent clearing (in relative terms), being situated in a more enduring area of clearance that was maintained to some degree throughout the Neolithic, but this was not a pristine area entirely stripped of woodland cover - woodland periodically regenerated here too (Campbell and Robinson 2007: 27).

The evidence from the English Midlands points to the way in which sources of environmental data other than pollen can begin to provide important detail on the character of the Neolithic landscape. One particularly important additional strand of data is the insect record. An important recent review, for example, found that in general the fossil beetle record both complements and adds new detail to the pollen evidence from southern Britain (Whitehouse and Smith 2010). The beetle record of the later Mesolithic is dominated by tree-indicating taxa, but with occasional indicators of more open areas, particularly in floodplain locations. In the period 4,000-2,000 cal $\mathrm{BC}$, there is evidence for increased landscape complexity with a trend towards more open environments, but throughout this period, tree and wood decay communities remained significant. The insect evidence also indicates that woodland in the early Neolithic was also rich with dead wood, much more so than current woodland contexts (Whitehouse 2006: 1767). Overall the beetle evidence provides a picture of 'a shifting mosaic landscape', in which tree clearance, regeneration, and the activities of grazing animals were important (Whitehouse and Smith 2010: 549). Like the pollen record, the palaeoentomological record also suggests changes to landscape and the character of human activity in the middle Neolithic period of c. 3,500-2,500 cal $\mathrm{BC}$, with evidence of re-afforestation and more limited clearings and areas of grazing (Whitehouse and Smith 2009: 549). The evidence for the Neolithic woodland outlined by Whitehouse and Smith accords well with Robinson's suggestions from a different review of the insect evidence, that the Neolithic woodland generally was a mosaic of small-scale clearings, abandoned clearings, stands of secondary growth woodland, and some undisturbed primary woodland (Robinson 2000). Overall, while the pollen and insect evidence indicates that impacts were being made on the woodland in the Neolithic, this remained a woodland that is generally difficult to parallel today: the presence of wildwood insect fauna and species of woodland insects that are now extinct or occur only rarely in contemporary environments suggests that the character of the woodland was very different from any woodland that exists in the modern landscapes of northern Europe (Robinson 2000). 


\section{SEEING THE WOOD FOR THE TREES}

'In the history of human transformation of the earth, one of the key processes must be deforestation'.

(Williams 2000: 28)

The palaeoecological evidence for the character of northern Neolithic landscapes can help begin to reinvigorate our accounts of the Neolithic landscape with evidence for the lively and ever-changing character of the forest and wider landscape that characterised the first agricultural landscapes of Europe. What these sources reveal is the to-and-fro of landscape transformation and the patterns of vegetation that characterised the landscapes of northern Europe throughout the Neolithic. Forest, grassland, and 'managed' forest along with the human and animal occupants of these environments can be considered together to have created the landscapes of northern Europe during the Neolithic. It was only in the Chalcolithic and Early Bronze Age that the more open landscapes familiar today began to fully take shape in many landscapes, aided undoubtedly by a new agent of transformation - the introduction of metal tools.

The short review of the palaeoenvironmental and other evidence for the environments of the Neolithic in northern Europe outlined here cannot be regarded as comprehensive, but it provides a baseline of evidence for characterising the kinds of landscapes that people would have encountered on a daily basis in the Neolithic. Overall the evidence from the regions of northern Europe highlighted above suggests that woodland remained an important element of many landscapes during the Neolithic. In terms of clearance, at a general level, a decline in woodland cover can be detected from the early 4th millennium cal BC onwards across northern Europe coincident with the onset of agriculture, but woodland clearance in a long-term perspective appears gradual in most regions (Fyfe et al. 2013: 144). A common pattern is for the slighter clearance impacts evident in the Neolithic to be superseded by larger, landscape-scale deforestation events in the Bronze Age or later (Berglund 1988: 250; Brown 1997: 134; Sjögren 2006: 116; Tipping 1994). Indeed, woodland cover remained a major part of many northern Europe landscapes until the major clearance events of the High Middle Ages (Williams 2000: 28).

In the Neolithic, there is no doubt that in some landscapes, people and the new animals and plants introduced did have an effect on the composition and character of the environment, as occurred most obviously in landscapes such as that which surrounded the Céide Fields in Ireland. Nonetheless, clearance and landscape modification, even in cases such as the Céide Fields, was by no means necessarily permanent. My focus in the short summary of the palynological evidence for the Neolithic has been on the examples where clearance has been documented - there are many areas where the evidence suggests little alteration 
from late Mesolithic woodland conditions. In some regions such as Ireland and Scotland, obvious clearance episodes are restricted to the earlier Neolithic, with less evidence for landscape clearance in the middle Neolithic. In Sweden, in contrast, there is only weak evidence for clearing in the earlier Neolithic, with some increase in the middle Neolithic (Sjögren 2006). In England as elsewhere, the picture is of a mosaic of vegetation types, with a general, but by no means consistent trend for more open landscapes in the first half of the 4th millennium followed by less clear-cut indications of forest impact during the period c. 3,500-2,500 cal $\mathrm{BC}$, with renewed phases of clearance towards the middle or end of the 2nd millennium BC (Whitehouse and Smith 2010: 549). Certain landscapes appear to have been more open, in particular some of the betterknown chalkland landscapes (Allen and Gardiner 2009; French 2009), but in all cases landscape change appears to have been piecemeal and landscape form was never stable, always changing (Fyfe et al. 2013). As Whitehouse and Smith note (2010: 551), it is clear that the Neolithic woodland was a constantly evolving and changing ecosystem - a world that was always becoming and never in stasis.

Further palaeoecological work will undoubtedly add significant detail to our accounts of change in the Neolithic environment. For example, almost all of the studies highlighted in this chapter lack detail on how overall percentages of arboreal pollen relate to actual impacts and levels of clearance in the Neolithic landscape (Caseldine and Fyfe 2006; Caseldine et al. 2008; though see Marquer et al. 2014). One of the few studies to do this, that at Derragh Bog in central Ireland, modelled the impacts of elm disease and an episode of landnam in the early 4th millennium BC in a $6 \mathrm{~km}$ area around Derragh Bog (Caseldine and Fyfe 2006). Here they found that the elm decline would have had a major effect on the overall vegetation composition of this landscape with an elm-dominated landscape being replaced by a more patchwork distribution of hazel, oak, and small areas of grass in the period following the initial loss of elm. In the landnam period, Caseldine and Fyfe estimate that a minimum of $12 \%$ of the land area would have been open, with areas already naturally open being exploited by humans for agriculture; other areas will have been open through the effects of wind throw, exacerbated by the effects of disease and animal or human activity (Caseldine and Fyfe 2006: 642). Modelling work such as this will undoubtedly flesh out our pictures of human-environment interrelationships and refine our understandings of how the environment changed in character at a site and landscape level during the Neolithic, and indicate how both climate shifts and change induced by humans and non-humans contributed to the form of the landscape in the Neolithic.

The picture painted here therefore is at present rather generalised and requires further work on a local, regional, national, and international scale. It is, however, sufficient to show the continuing relevance of woodland to many Neolithic lives and landscapes. The overall evidence from the Neolithic of 
northern Europe suggests landscapes in flux, with woodland cover receding and regenerating over time with different temporal rhythms in different regions and in different valleys. Clearance of woodland became more of a routine part of life and is clearly much more evident from the early 4th millennium cal BC onwards. Many places remained forested, while others may have become important due to the more open conditions present. The large-scale monumental complexes such as those found on Cranborne Chase in southern England, for example, would have perhaps gained part of their significance from the fact that the landscape around the monuments was different from those elsewhere (Allen and Gardiner 2009: 61; French et al. 2003; Tilley 2007). Much of the evidence for clearance in these landscapes suggests pastoral activity (Robinson 2000; Wilkinson and Straker 2008: 110). These may well have been areas that were as significant as communal grazing areas as much as they were foci for monument building (Lelong and Pollard 1998: 49). The Stonehenge landscape may have also become a very important area for prehistoric communities due to the development of stable and open grassland by the later Neolithic in this region, which may also have been grazed relatively intensively (French et al. 2012: 31). Through greater levels of woodland clearance, these locations would have taken on different sensory qualities and would have become more suited to particular agricultural lifeways and tasks. However, even in landscapes where many monuments were built, woodland could remain an important part of landscape cover, inhabitation, and perception (Campbell and Robinson 2007).

Clearance, small-scale and large, would have altered the woodland of the Neolithic. A range of ecological and climatic changes would also have altered the forest as the 4th millennium progressed (Brown 1997). Indeed, existing, naturally created clearings may have been augmented in the Neolithic by opportunistic exploitation by humans (Brown 1997: 140). The increased evidence for coppiced woodlands in the Neolithic also confirms that woodland was increasingly bound into the patterns of human occupation and exploitation that developed in the Neolithic (Andersen 1992; Göransson 1994b). Cereals were cultivated in small gardens in plots presumably cleared of woodland or using already open areas. New types of animals - cattle, pigs, sheep, and goats were also brought northwards, and both the environment and the human and nonhuman communities living within were altered through these processes of introduction. In this respect, multiple agencies were at work in creating the Neolithic, and very soon the introduced plants and animals were an integral part of the environment of northern Europe - Neolithisation entailed a largely irreversible process of change, only some of which was orchestrated by humans.

Overall, the kinds of landscape encountered in late Mesolithic and early Neolithic life is one difficult for us to imagine today. Very few areas in Europe today have forest conditions similar to those of the earlier Holocene. Some 
woodlands of Europe contain old growth woodland, where the principal means of survival has been its inaccessibility. However, few of these woodlands match the conditions that would have occurred in late Mesolithic and early Neolithic forests. One of the few modern parallels is Białowieża national park which straddles the border between Belarus and Poland (Hilbers 2005) (Figure 2.1). The park survives as a very rare example of the kinds of forested environment that may have existed in the Mesolithic and Neolithic in Europe (Peterken 1996: 44). In Białowieża different forest types grow in different areas of the park according to geology, soils, and environmental conditions. The

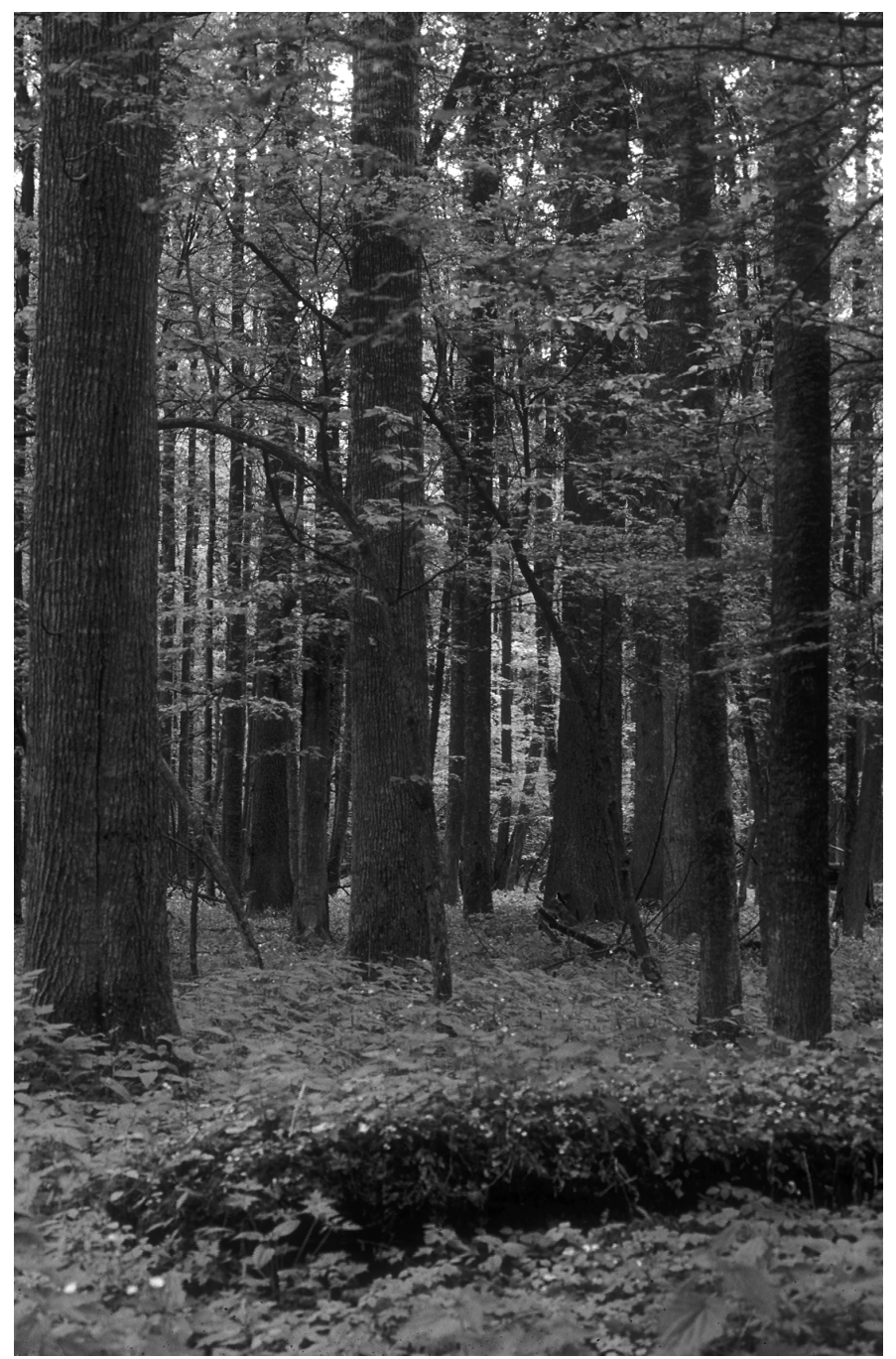

2.1 The dynamic environment of Białowieża forest on the borders of Poland and Belarus. (C) Fred Hoogervorst. Long, straight oak tree trunks from dense mixed oak woodland can be seen in the background. In the foreground, a fallen oak trunk is gradually being subsumed back into the soil of the forest floor. 


\section{CONCLUSIONS}

most common forest type is oak-dominated, closed-canopy forest. Within the forest, oak trees along with other species such as lime, spruce, and alder grow exceptionally tall as they compete with one another for sunlight in the dense forest conditions that exist in Białowieża. Trees reaching over $6 \mathrm{~m}$ in girth survive in the woodland today. The forest floor is littered with dead wood and there is a great range of insects, birds, and fungi that make their homes in the fallen logs, which can take up to 50 years or more to fully decay. A diverse range of animals live in the forest. These include beavers that rework the local environment every few years by making dams that redivert watercourses and impact the forest vegetation in dramatic ways. Insects rare or extinct elsewhere in Europe also make their lives in the rich ecosystem of Białowieża. Without drainage ditches of the type found across modern Europe large areas of Białowieża also consist of bog, marsh, and alder swamp. The woodland of Białowieża is an incredibly dynamic environment - clearances are constantly created by storm events and the actions of humans and animals, but these clearances rarely endure for any length of time. Over a period of days, months, or years these clearances tend to regenerate, and the regenerative powers of the forest is difficult to curtail. The exact composition of Białowieża is not a direct parallel for all of the forest types that existed in prehistoric northern Europe. However, the diversity and dynamism of this environment, the monumentality of some of the trees within this forest, and the regenerative powers of the environment perhaps provide a closer model for some of the landscapes of northern Europe that existed in the Neolithic than the vast majority of the more open landscapes or lightly wooded areas that exist today in Britain and south Scandinavia.

\section{CONCLUSIONS}

The palynological and fossil insect evidence outlined in this chapter provides a rich detailed data set for understanding the woodlands of the Neolithic. The challenge for Neolithic studies is to use the information provided by techniques such as palynology to reinsert these dynamic environments into our accounts of Neolithic life and experience. The northern European forests of the Neolithic would have been highly variable ecosystems which would have dictated and been bound up in the realities of Neolithic life. Trees of a character rarely found in Europe today would have towered over human settlements and natural processes such as wind blow, forest fires, and forest succession would have constantly changed the character of the forest environment. It was within this dynamic context that the first farming practices were introduced to northern Europe, and the palynological research provides clear evidence for the ways in which humans (and introduced animals) began to have an impact on the environment through processes of clearance and new ways of using the 
materials of the forest. Neolithic communities in many landscapes lived in a shifting mosaic of clearings, primary forest, secondary growth, and abandoned clearings. People used the forest in more intensive ways with greater evidence for coppicing - the forest provided for Neolithic life. The environment also acted back - the forest could recolonise unmaintained clearances and would invade garden plots without careful investments in tending and maintenance by Neolithic communities. Indeed, we should not underestimate the dramatic speed at which woodland can regrow and recolonise after clearance - the forest has a powerful agency. In the following chapters I hope to further bring out the dynamism of the Neolithic environment, but in the next chapter we will examine how people worked with the materials of environment and the environment itself to create the context for Neolithic life. 